tion. The girl underwent successful surgery and is doing well 1 year after the resection. Sinus tachycardia and PVC were no longer recorded after surgery, suggesting a cause and effect relationship between the aneurysm and the arrhythmias.

The pathologic study showed a mucus-filled bronchogenic cyst of approximately $1 \mathrm{~cm}$ in its greatest diameter. The cyst was located within the wall of the aneurysm. The cyst lining was in part ciliated, columnar of respiratory type, and in part polyptychial cubical, with interposed mucous cells and foci of squamous metaplasia with mild lymphocyte infiltrates. Irregular bundles of smooth muscle cells were present in the thickness of the cyst wall (Figure 1, B, F).

\section{Discussion}

The bronchogenic cyst was a non-expected finding at the pathologic study of the removed aneurysm that constituted the major lesion. This case documents the possible presence of a bronchogenic cyst within the wall of an aneurysm of the pars membranacea septi.

Prior reported cases are different from the present one because the bronchogenic cysts were large enough to be detected as cysts at the echocardiography or computed tomography scan study. ${ }^{1-5} \mathrm{In}$ our patient the lesion diagnosed with echocardiography was the aneurysm. A small cystic space was suspected (Figure 1, A) but did not influence the echocardiography diagnosis and the surgical decision.

A bronchogenic cyst is a benign lesion. Surgical treatment is controversial, ${ }^{2}$ especially in patients without clinical symptoms. However, the benignant nature of the cyst is unknown before pathologic examination. Moreover, the cyst may progressively enlarge $^{1}$ because of mucus accumulation and inflammation of the wall. Analogously to other cardiac masses, it may trigger complications such as arrhythmias, conduction disturbances, obstruction of blood flow, or embolization. ${ }^{2-4}$

\section{References}

1. Soeda T, Matsuda M, Fujioka Y, Doui K, Maruhashi H. A case report of a huge bronchogenic cyst originated in the atrial septum. Nippon Kyobu Geka Gakkai Zasshi. 1996;44:1781-6.

2. Kawase Y, Takahashi M, Takemura H, Tomita S, Watanabe G. Surgical treatment of a bronchogenic cyst in the interatrial septum. Ann Thorac Surg. 2002;74:1695-7.

3. Lee T, Tsai IC, Tsai WL, Jan YJ, Lee CH. Bronchogenic cyst in the left atrium combined with persistent left superior vena cava: the first case in the literature. Am J Roentgenol. 2005;185:116-9.

4. Weinrich M, Lausberg HF, Pahl S, Schafers HJ. A bronchogenic cyst of the right ventricular endocardium. Ann Thorac Surg. 2005;79:e13-4.

5. Prates PR, Lovato L, Homsi-Neto A, Barra M, Sant'Anna JR, Kalil RA, et al. Right ventricular bronchogenic cyst. Tex Heart Inst J. 2003;30: 71-3.

\title{
Coronary artery bypass grafting and biventricular pacing efficacy: Do past trials dictate a change in future practice?
}

Omid Hajiseyedjavadi, MD, MSc, Michael Pasque, MD, Marc Moon, MD, Ralph Damiano, MD, Teodoro Mucha, BS, Keith Hebert, BS, and Nader Moazami, MD, St Louis, Mo

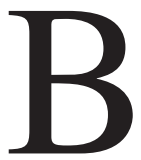
iventricular pacing, or chronic resynchronization therapy (CRT), has been increasingly used in management of patients with class III to IV heart failure who have evidence of interventricular conduction delay. Despite the widespread use of this therapy, the endocardial procedure required for left ventricular (LV) lead placement can be labor

From Washington University, Barnes Hospital, St Louis, Mo.

Medtronic is the sponsor of the MIRACLE trial, which provided the data for this study. R.D. reports consulting and lecture fees from Medtronic. T.M. and K.H. report that they are employees of Medtronic and hold stock options in the company.

Received for publication Aug 27, 2005; accepted for publication April 14, 2006.

Address for reprints: Omid Hajiseyedjavadi, MD, MSc, 12513 E Lupine Ave, Scottsdale, AZ 85259 (E-mail: javadio@wustl.edu).

J Thorac Cardiovasc Surg 2006;132:974-5

$0022-5223 / \$ 32.00$

Copyright $\odot 2006$ by The American Association for Thoracic Surgery doi:10.1016/j.jtcvs.2006.04.049 intensive and fails in approximately $10 \%$ of patients. ${ }^{1,2}$ In fact, the LV lead placement in the Multicenter InSync Randomized Clinical Evaluation (MIRACLE) trial was associated with the highest rate of complication. ${ }^{1}$ Large number of patients undergoing cardiac surgery have some degree of systolic dysfunction in conjunction with interventricular conduction delay. Prophylactic epicardial LV lead placement in this setting may be beneficial and can be performed with ease. In the absence of any trials showing the beneficial effects of prophylactic LV lead placement during cardiac surgery, we sought to perform a subgroup analysis of the Multicenter InSync Implantable Cardioverter-Defibrillator (ICD) Randomized Clinical Evaluation (MIRACLE-ICD) trial to determine whether the beneficial effects of biventricular pacing continue to be evident in patients who had previously undergone coronary artery bypass grafting (CABG).

\section{Methods}

A review of the raw data from the MIRACLE-ICD trial was performed to determine the response to CRT of patients with coronary artery disease who received biventricular therapy long 
TABLE 1. Clinical outcomes: Changes at 6 months

\begin{tabular}{|c|c|c|c|c|c|}
\hline \multirow[b]{2}{*}{ Outcome measure } & \multicolumn{2}{|c|}{ CRT on $(n=106)$} & \multicolumn{2}{|c|}{ CRT off (n = 116) } & \multirow[b]{2}{*}{$P$ value } \\
\hline & Value & $\mathbf{n}$ & Value & $\mathbf{n}$ & \\
\hline $\begin{array}{l}\text { Minnesota Living with Heart Failure } \\
\text { Questionnaire score change }\end{array}$ & $-18.4 \pm 23.4$ & 94 & $-9.9 \pm 19.4$ & 101 & .007 \\
\hline NYHA functional class & $-0.6 \pm 0.8$ & 93 & $-0.4 \pm 0.7$ & 105 & .02 \\
\hline 6-min hall walk (m) & $57.6 \pm 105.9$ & 87 & $60.4 \pm 122.6$ & 100 & .87 \\
\hline Oxygen consumption (mL/[kg $\cdot \min ])$ & $0.6 \pm 2.6$ & 72 & $0.2 \pm 3.4$ & 84 & .47 \\
\hline Exercise time (s) & $54.4 \pm 129.7$ & 72 & $-31.3 \pm 180.4$ & 86 & .0007 \\
\hline
\end{tabular}

All values are mean \pm SD.

after CABG. A subgroup analysis from 363 patients with ischemic heart disease enrolled in the MIRACLE-ICD trial (New York Heart Association [NYHA] functional class III/IV symptoms, ejection fraction $\leq 35 \%$, QRS $\geq 130 \mathrm{~ms}$, and indication for ICD) revealed $222(61 \%)$ with history of CABG. This subgroup formed the basis of this analysis. This group of patients had been prospectively randomly assigned $1: 1$ to 6 months of CRT versus no pacing. From this subset, clinical end points were analyzed with 2 -sided Student $t$ tests with mean $\pm \mathrm{SD}$ changes from baseline to 6 months.

\section{Results}

Mean age was 69 years, and $92 \%$ of the patients were male. Mean values were as follows: time from CABG to CRT, 9.2 years; number of vessels bypassed, 3.5; ejection fraction, $21.5 \%$; and NYHA functional class, 2.8. Table 1 summarizes the outcomes.

\section{Discussion}

Biventricular pacing has been popularized as a new nonpharmacologic therapy for patients with chronic heart failure. In the 1980s, interest in pacing therapy for heart failure largely revolved around manipulation of the atrioventricular delay in patients with heart failure who were implanted with dual-chamber pacemakers that used right atrial and right ventricular leads. ${ }^{3}$ Shortening the atrioventricular delay appeared to be beneficial in patients with first-degree atrioventricular block and in those with Doppler evidence of presystolic mitral regurgitation. ${ }^{2,4}$ Early reports of biventricular pacing involved epicardial LV leads. In 1994, Cazeau and associates and later Foster and colleagues ${ }^{5}$ investigated pacing after CABG. Both groups found that maximal hemodynamic benefit was derived from a combination of atrial and biventricular pacing, especially when ventricles contracted sequentially and in synchrony. The underlying concept of CRT was that the efficiency of the heart as a pump would be increased if the start of systole could be synchronized by simultaneously pacing the two atria, followed by the ventricles.
In this subgroup analysis of a randomized, prospective trial, we demonstrated that patients who have previously undergone CABG derive benefits from CRT similar to those seen in the large cohort of patients in the MIRACLE-ICD trial. More specifically, the cohort of patients with NYHA class III or IV symptoms, ejection fraction no greater than $35 \%$, QRS at least $130 \mathrm{~ms}$, and indication for ICD demonstrated a predictable benefit from resynchronization. Although there may be other groups of patients with predictable benefit from an intraoperative lead placement, our data address the benefit for this particular cohort at this time. It is our contention that improvements in functional capacity of this subgroup of patients is a compelling argument in favor of prophylactic epicardial LV lead placement at the time of cardiac surgery. The potential difficulty of percutaneous lead placement-related to difficulties in cannulating the coronary sinus, variable anatomy, unsuitable target veins, diaphragmatic stimulation, and lead dislodgment-can be circumvented if these leads are placed during cardiac surgery.

\section{References}

1. Young JB, Abraham WT, Smith AL, Leon AR, Lieberman R, Wilkoff $\mathrm{B}$, et al. Combined cardiac resynchronization and implantable cardioversion defibrillation in advanced chronic heart failure: the MIRACLE ICD Trial. JAMA. 2003;289:2685-94.

2. Brecker SJ, Xiao HB, Sparrow J, Gibson DG. Effects of dual-chamber pacing with short atrioventricular delay in dilated cardiomyopathy. Lancet. 1992;340:1308-12.

3. Haywood G. Biventricular pacing in heart failure: update on results from clinical trials. Curr Control Trials Cardiovasc Med. 2001;2:292-7.

4. Nishimura RA, Hayes DL, Holmes DR Jr, Tajik AJ. Mechanism of hemodynamic improvement by dual-chamber pacing for severe left ventricular dysfunction: an acute Doppler and catheterization hemodynamic study. J Am Coll Cardiol. 1995;25:281-8.

5. Foster AH, Gold MR, McLaughlin JS. Acute hemodynamic effects of atrio-biventricular pacing in humans. Ann Thorac Surg. 1995;59:294300 . 